
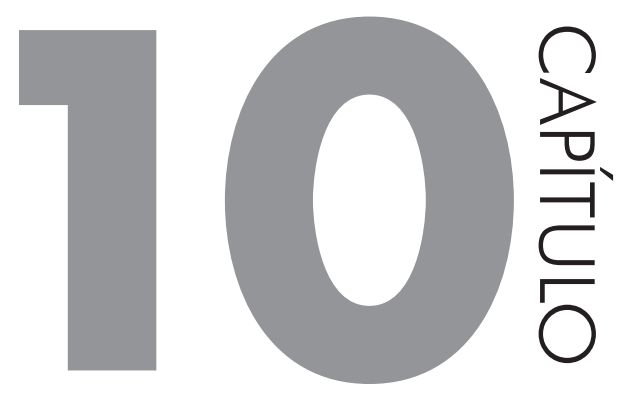

\title{
DESAFIOS PARA O MONITORAMENTO DA QUALIDADE DA ÁGUA DE LASTRO
}

NEWTON NARCISO PEREIRA

\subsection{INTRODUÇÃO}

Um dos principais desafios que ainda afligem as autoridades marítimas e portuárias refere-se ao resultado final da qualidade da água de lastro tratada pelos navios e ou despejada nos portos.

Com a entrada em vigor da BWMC, os navios terão um prazo de pelo menos 5 anos para instalar sistemas de tratamento de água de lastro a bordo. Embora, exista uma grande discussão ainda na literatura sobre a eficiência destes sistemas. Até o presente momento 5 sistemas foram homologados pela USCG. Isso deve-se ao fato da USCG ter seus próprios critérios de avaliação dos sistemas de tratamento, considerando os parâmetros da IMO como referência (Bastista et al., 2017). Além disso, os estados americanos podem também desenvolver seus próprios critérios em termos da performance destes sistemas, como é o caso da Califórnia.

Diante de uma série de evidencias do mercado, a maior parte dos fabricantes de sistemas de água de lastro ainda não conseguiram alcançar os padrões de zero micro-organismos na água (Cohen et al., 2017; Cohen e Dobbs, 2015; Pereira et al., 2016). Deste modo, a Califórnia modificou seus padrões de restrição aceitando os parâmetros IMO e a certificação USCG, adiando para 2030 a adoção dos parâmetros mostrado no Capítulo 5 (Batista et al., 2017). Mesmo a adoção de 
BWMS não existe a garantia de que a qualidade da água de lastro despejada nos portos estarão dentro dos padrões que minimizem os riscos de bioinvasão. Isso devido, a dinâmica da sobrevivência dos organismos dentro dos tanques de lastro, bem como, das condições reais de operação dos navios e a presença de sedimentos e organismos muitas vezes desconhecidos.

Por outro lado, como ainda existe um prazo para que os navios tenham estes BWMS instalado, os navios que encontram-se em operação em sua maioria ainda devem realizar a troca da água de lastro. Ou seja, os atuais métodos existentes para a verificação da real troca de água de lastro limitam-se à determinação da salinidade, por meio de um refratômetro (Pereira 2012). Em conjunto realiza-se a pesquisa em Diários de Bordo e Diários de Máquina para verificar a origem da água de lastro do navio. Os métodos citados além de consumirem um tempo razoavelmente longo, ainda estão sujeitos a informações nem sempre confiáveis (Pereira et al., 2014, Cohen e Dobbs, 2015).

Para a verificação a bordo dos navios é necessário que os tanques sejam abertos e amostras sejam coletadas. Nós verificamos a bordo dos navios os problemas relacionados com a abertura dos tanques, em que demandam enorme esforço da tripulação, além dos pontos de inspeção e a necessidade de pessoal especializado para sua realização das coletas.

A)

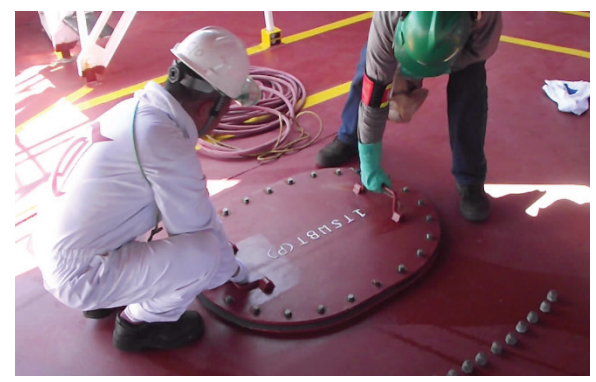

C)

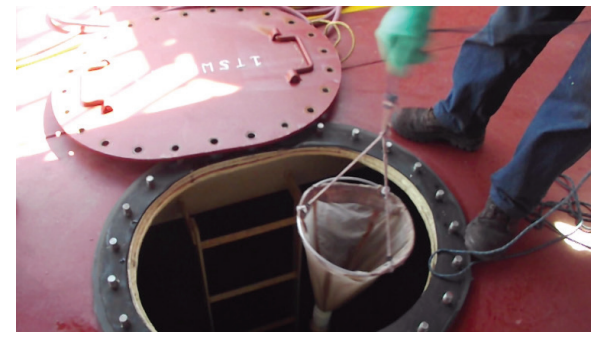

B)

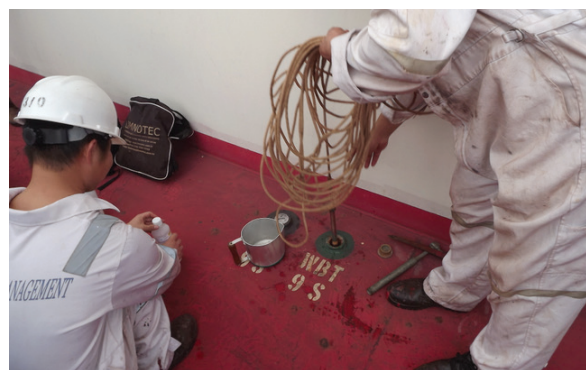

D)

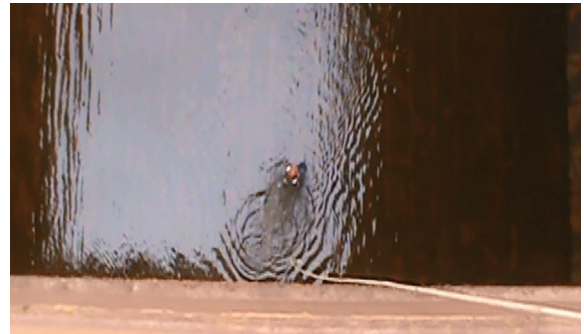

Figura 55 Ações para coleta de amostra de água de lastro a bordo dos navios. A) Procedimento para aberto de tanques do convés. Durante esta operação foram gastos cerca de 15 minutos em função do estado das porcas de abertura do tanque. B) Coleta de amostra por meio do tubo de sondagem do tanque. C) coleta de amostra com a rede de fitoplâncton dentro do tanque. D) coleta de água de lastro do tanque de carga do navio 
E)

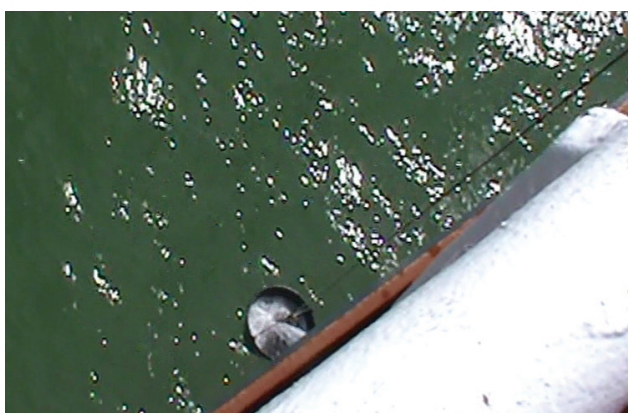

F)

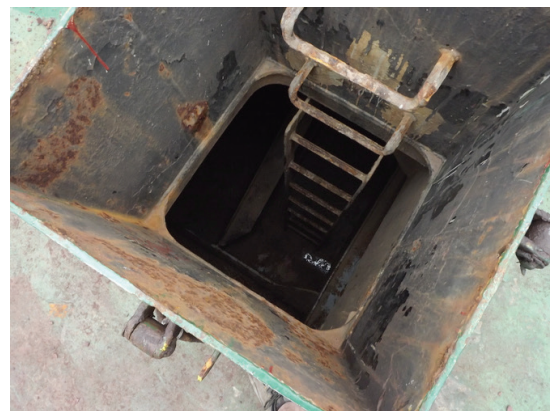

Figura 56 Dificuldade de acesso e coleta da água de lastro. E) devido à dificuldade de acessar o tanque a água de lastro foi coletada pelo convés do navio durante o processo de deslastre do navio junto ao porto. F) acesso ao tanque de lastro pelo convés

O custo de mobilização de equipe para esse procedimento ainda não foi reportado na literatura, porém existe dificuldades reportadas para esta operação. Além disso, existe o problema dos sedimentos que também tem elevado o potencial de impacto e que não são detectados pelos instrumentos atuais (Prange e Pereira, 2013).

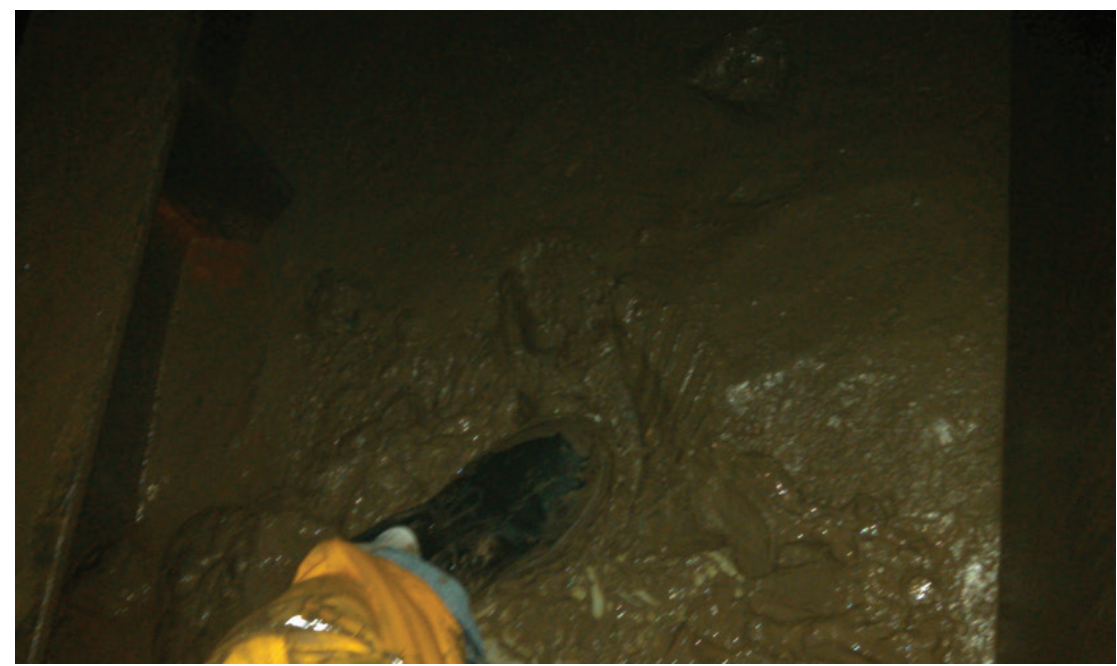

Figura 57 Presença de sedimento no fundo do tanque de água de lastro

A questão do monitoramento da água de lastro é algo que tem sido estudado ao longo do tempo e sistemas foram desenvolvidos por empresas que buscam oferecer ao mercado uma solução. Uma destas soluções é Ballast-Check desenvolvido pela Turner Design, que consiste de um sistema que mede a fluorescência das algas na água de lastro. 
G)

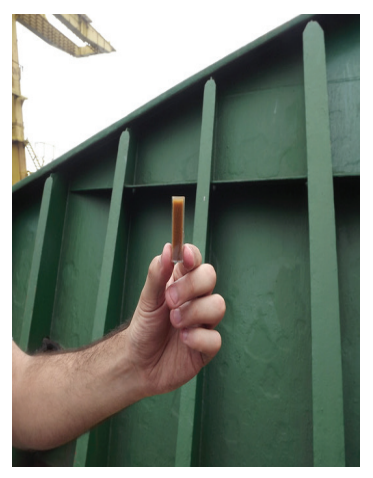

$\mathrm{H})$

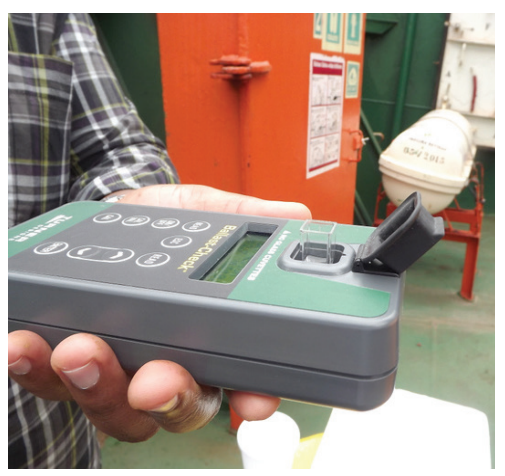

I)

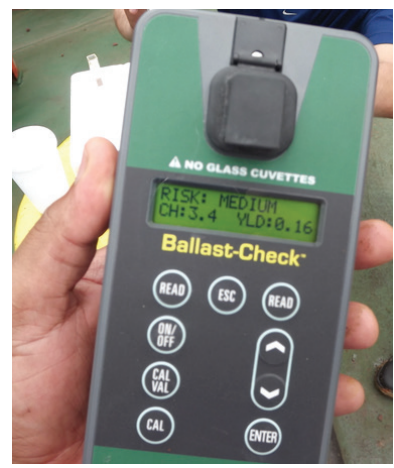

Figura 58 Exemplo de utilização do Ballast-Check. A) Coleta de amostra de água de lastro. B) inserção da amostra no aparelho. C) Resultado apresentando o grau de risco medido pela amostra analisada

Mesmo com este sistema não é possível realizar a análise de parâmetros físico químicos. Segundo o site do fabricante o mesmo atende os critérios D-2 da IMO, mas no que tange apenas a análise da presença de algas.

Uma das alternativas possíveis para minimizar o problema da verificação da qualidade da água de lastro despejada nos portos seria a possibilidade de um monitoramento remoto da água de lastro. Esta seria uma forma de monitorar as características físico química e biológica da água coletada pelos navios, trocada e tratada por meio dos BWMS's. Ao revisarmos as características dos BWMS disponíveis no mercado nenhum deles permitem o monitoramento remoto da qualidade final da água tratada. Isso seria uma obrigação das autoridades marítima, caso queira verificar a qualidade da água despeja por um determinado navio dotado de BWMS.

Neste quesito, surge uma questão muito importante que refere-se a forma de como mensurar a presença dos organismos após o tratamento da água de lastro? Como verificar se não houve alteração nas propriedades físico químicas da água após o tratamento?

Essas perguntas são difíceis de serem respondidas, por se considerarmos o padrão utilizado pela IMO para verificação das espécies presentes na água de lastro a medida é a presença de um numero de organismos por $\mathrm{m}^{3}$. Ou seja, para validar se um determinado sistema está trabalhando de maneira efetiva, a verificação a ser realizada deve ser por meio da coleta de pelo menos $1 \mathrm{~m}^{3}$ de água e realizar as análises. Neste sentido, pergunta-se: (1) como coletar $1 \mathrm{~m}^{3}$ de água de lastro no porto de cada tanque e conduzir a contagem dos organismos conforme o padrão D-2 da IMO? Outras perguntas neste quesito: como reduzir o tempo de 
inspeção da água de lastro para navios que trocam esta água no oceano? É possível monitorar esta água remotamente?

Atualmente, (1) estão sendo desenvolvidos sistemas para contagem de organismos presentes na água de lastro após o deslastre do navio utilizando fluxo citométrico, com objetivo de detectar partículas na água (BAKALAR, 2014). Um Outro sistema baseia-se na identificação de células vivas na água por meio de Trifosfato de adenosina (ATP), que consiste é um nucleotídeo responsável pelo armazenamento de energia em suas ligações químicas. Ou seja, a contagem destas ligações permite identificar a quantidade de organismos vivos na água de lastro (CURTO et al. (2017). Testes conduzidos pelos autores mostraram-se promissor para a contagem de organismos presentes na água de lastro após o tratamento da água de lastro.

No entanto, ainda existe uma questão (2) a ser respondida em relação aos navios que não dispõem de BWMS. Como vimos ao longo deste livro, muitos problemas foram reportados em relação a eficiência da troca da água de lastro e procedimentos de verificação que afligem não somente o Brasil e outros países.

Para isso, em conjunto com o Laboratório de Microeletrônica da Escola Politécnica da Universidade de São Paulo foi desenvolvido um sistema remoto de monitoramento da troca da água de lastro dos navios. Este sistema foi instalado no M/V Norsul Crateus que foi enviado para scrapping em 2016, mas permitiu que preciosos resultados fossem coletados durante o período de quase dois anos de investigação.

O sistema foi desenvolvido para monitorar os parâmetros físico químicos da água de lastro por meio de sensores como turbidez, salinidade, oxigênio dissolvido, $\mathrm{pH}$ e temperatura. Conforme reportado na literatura, uma dificuldade existente era identificar exatamente as coordenadas geográficas da captura da água de lastro. Deste modo, o conceito aplicado neste desenvolvimento consistiu de correlacionar os dados coletados pelos sensores com a posição geográfica do navio durante a viagem.

Esses dados eram arquivados em um controlador sendo inalterável e transferido remotamente via satélite para um servidor de internet numa conta de e-mail. Os dados recebidos eram capturados por um sistema que retirava os dados armazenados no servidor e os apresentam numa interface gráfica as medidas de cada sensor.

Deste modo, a seguir irei apresentar os principais desafios para o desenvolvimento e instalação deste sistema a bordo do navio. 


\subsection{PORQUE DESENVOLVER UM SISTEMA?}

Quando pensamos no monitoramento da água de lastro em 2010, a primeira pesquisa que realizamos foi verificar se já existiam fornecedores de sistemas comerciais que permitissem realizar este monitoramento. Verificamos que existiam diversos fornecedores de sondas para monitoramento de parâmetros físico, químicos e até biológicos da água. Estas sondas chamadas de multiparametros são amplamente utilizadas nas áreas de oceanografia e monitoramento ambiental.

Nossa pesquisa mostrou que estes sistemas conseguiam realizar o monitoramento dos parâmetros de qualidade de água, mas de maneira estacionaria. O primeiro desafio surgiu em função do fato do navio ser dinâmico e a coleta da água de lastro ocorrer durante a viagem do navio.

Quando consultamos a literatura verificamos que Raid et al., (2007) realizaram um monitoramento da água de lastro navios utilizando sondas multiparâmetros convencionais, adaptadas para serem instaladas por meio de um suporte no tanque de lastro dos navios.

Contudo, havia um inconveniente que estes equipamentos não conseguiam transmitir as informações em tempo real, bem como, não correlacionavam os parâmetros medidos com a posição do navio. Deste modo, os autores precisam aguardar o navio atracar para realizar a coleta dos dados armazenados na memoria da sonda.

Eles realizam cerca de 10 viagens monitorando dois navios com o mesmo método. Alguns problemas foram identificados em relação a vida útil dos sensores dentro dos tanques que precisavam ser substituídos a cada 3 meses, além dos problemas relativos a tripulação com manuseio dos equipamentos. Contudo, foi um estudo pioneiro em termos de monitorar a qualidade da água de lastro dentro dos tanques de navios mercantes.

Uma forma de mitigar problemas desta natureza é a utilização de um monitoramento remoto. Deste modo, devido as dificuldades de identificar um equipamento apropriado para ser instalado em tanques de lastro, foi que tivemos a ideia de construir um próprio sistema com esta finalidade.

O sistema de monitoramento da qualidade da água de lastro a bordo dos navios foi concebido com uma característica genérica. Isso significa dizer que a ideia principalmente do conceito deste sistema era permitir a coleta de dados do maior número de sensores possíveis, prevendo inclusive a utilização de sensores biológicos. O modelo conceitual do sistema está ilustrado na Figura 59. 


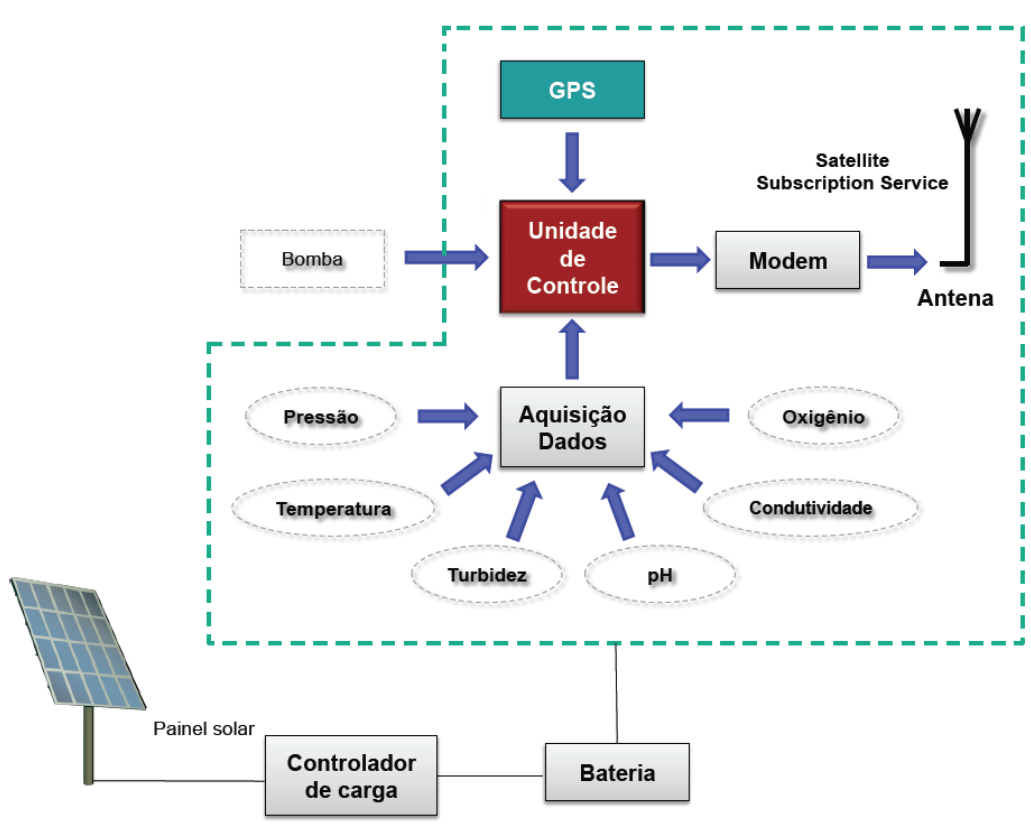

Figura 59 Concepção do sistema de monitoramento da água de lastro a bordo dos navios

O sistema foi composto pelos seguintes blocos funcionais: (1) Unidade de controle: realizava o condicionamento de sinais de comunicação e coordenava a coleta e a troca de dados entre os demais módulos; (2) GPS: responsável por fornecer a informação de posicionamento da embarcação através do Sistema de Posicionamento Global (Global Positioning System). Os dados eram fornecidos segundo o protocolo NMEA 0183; (3) Conversor analógico-digital: efetuava a conversão dos dados analógicos provenientes dos sensores para o formato digital. Estava configurado para receber sinais de até oito sensores, com sinal de saída do tipo corrente variando entre 4 e $20 \mathrm{~mA}$. A tensão de alimentação dos sensores no valor de $12 \mathrm{~V}$ era fornecida pelo sistema que inicialmente tinha sido previsto a utilização de sistema de painel solar para alimentar a bateria.

Os dados coletados eram transmitidos à unidade de controle através do protocolo RS-485; (4) Modem para comunicação via satélite: recebia os dados de posição e dos sensores processados pela unidade de controle e os transmitia via satélite utilizando a rede Orbcomm; (5) Sistema fotovoltaico: provia a alimentação $12 \mathrm{~V}$ de todo o sistema através de um painel solar. Uma bateria foi empregada para assegurar ao sistema autonomia mínima de três dias. Para realizar a gestão de energia do sistema fotovoltaico empregava-se um controlador de carga.

O desenvolvimento do sistema de monitoramento consistiu de diversas fases. Diversos testes foram desenvolvidos em laboratório para avaliar a operação dos sistemas de aquisição de dados. Para garantir que o sistema fosse instalado a 
bordo de um navio e garantisse a qualidade dos dados coletados e conservação dos sistemas desenvolvidos foi desenvolvido uma cobertura para os sistemas. O sistema foi encapsulado dentro de uma maleta metálica Figura 60.

G)

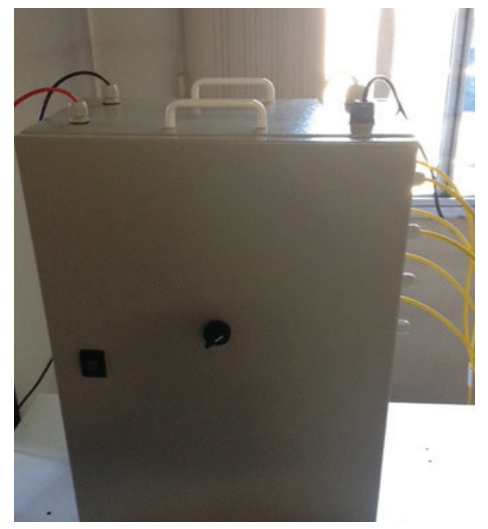

$\mathrm{H})$

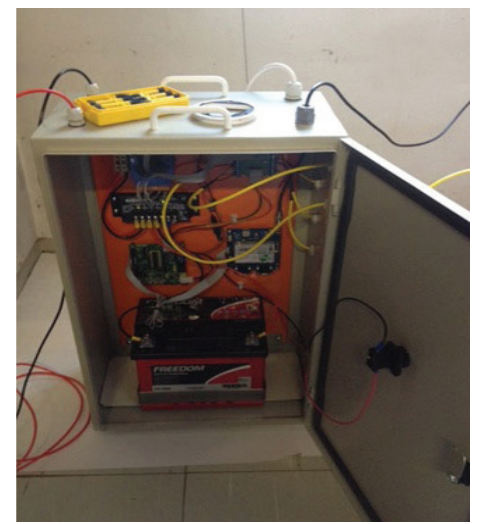

Figura 60 Sistema de monitoramento da água de lastro encapsulado

O cabo vermelho e preto eram os alimentadores de energia elétrica do sistema oriundas da placa de energia solar. Assim, essa energia carregava a bateria. O cabo branco pertencia ao GPS e o cabo preto da antena de recepção de dados. Cada cabo amarelo pertencia a um sensor acoplado ao sistema de monitoramento.

Os sensores foram posicionados estrategicamente dentro de uma gaiola. Ela foi desenvolvida para que pudéssemos manter todos os sensores numa mesma posição e confinados dentro de um ambiente propício para o monitoramento dentro do tanque (Figura 61).

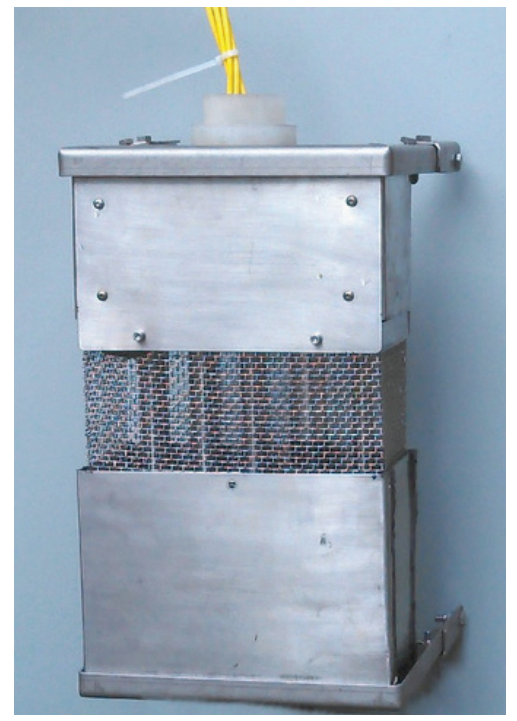

Figura 61 Gaiola desenvolvida para suporte dos sensores e fixação dentro do tanque de lastro 
Uma vez que todos os componentes foram desenvolvidos e testados em laboratório, o desafio foi conseguir um navio para a instalação do sistema e testar em escala real.

Para testar o sistema fora do laboratório a equipe desenvolvimento realizou um teste que consistiu da realização de uma viagem com todo o sistema instalado dentro de um veiculo na cidade de São Paulo.

Nesta ocasião foi possível verificar se estava ocorrendo a transmissão dos dados, bem como, a leitura dos sensores. Nós verificamos que o sistema funcionou plenamente durante este teste, o que nos deu maior incentivo para continuar a busca para instalação em um navio.

Fizemos contatos com diversas empresas de navegação no Brasil e no exterior e não obtivemos autorização para a instalação. Fizemos também uma apresentação deste sistema a Marinha do Brasil em 2013. Nesta ocasião tivemos uma rica discussão sobre sua utilização e esclarecimentos de dúvidas por parte da autoridade marítima brasileira.

Já em 2014, tivemos uma reunião com o diretor de engenharia da companhia de navegação Norsul, na qual nós somos muito agradecidos que nos cedeu a oportunidade de instalar este sistema a bordo de seu navio. O navio escolhido foi o M/V Norsul Crateus.

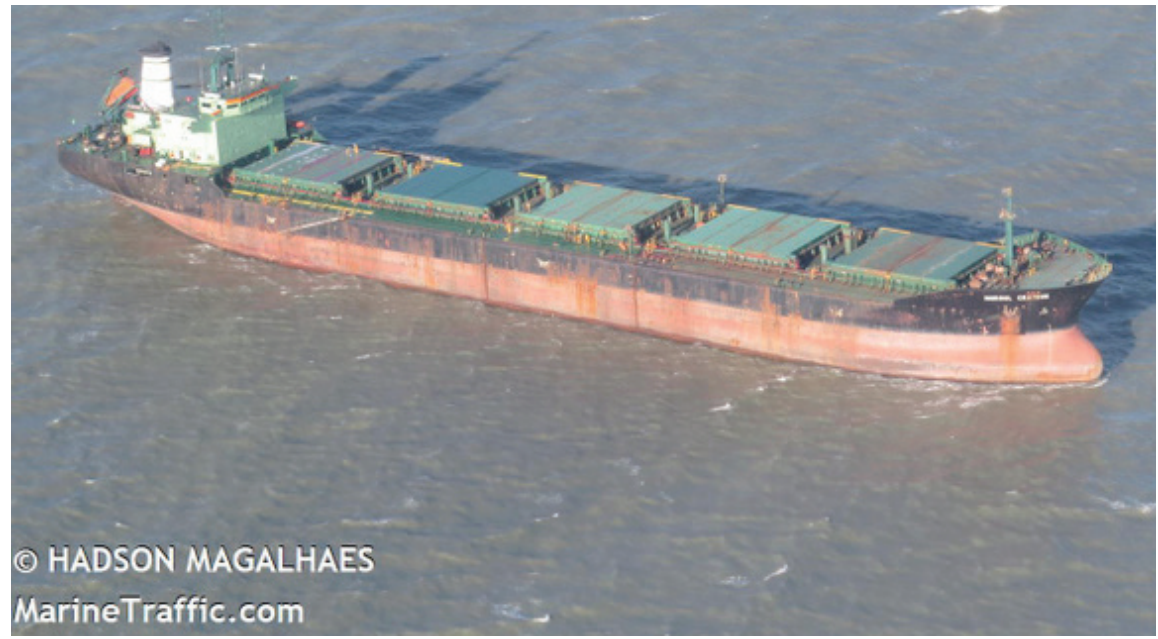

Figura 62 Foto do navio M/V Norsul Crateus enquanto estava em operação

Primeiramente, fizemos uma visita ao navio durante uma atracação no porto de Santos, em que foi realizada uma vistoria e uma longa conversa com a tripulação que nos ajudou a escolher um tanque de lastro que sempre era utilizado durante as operações do navio. Verificamos todos os pontos para a instalação dos equipamentos de comunicação, sensores e as adaptações necessários para a instalação do sistema. 


\subsection{INSTALAÇÃO DO SISTEMA A BORDO DO NAVIO}

Em 09 de abril de 2014 partimos de São Paulo para o porto de Santos para encontrar com o navio que estava atracado no Terminal da Usiminas fazendo a descarga de minério de ferro. Chegamos na parte da manhã com uma série de equipamentos e caixas. A primeira dificuldade foi passar pela segurança de acesso ao terminal que conferiu todos os componentes que estávamos levando para dentro do navio, devido o Código Internacional para Segurança de Navios e Instalações Portuárias - ISPS CODE.

Uma vez que conseguimos adentrar todos os equipamentos foram dispostos no navio e iniciamos o planejamento para instalação dos equipamentos. Foi escolhido o tanque de asa de bombordo, bem próximo a proa do navio.

A)

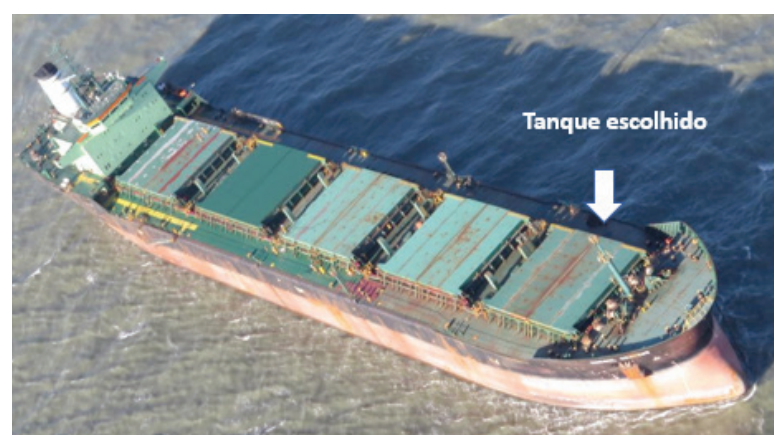

B)

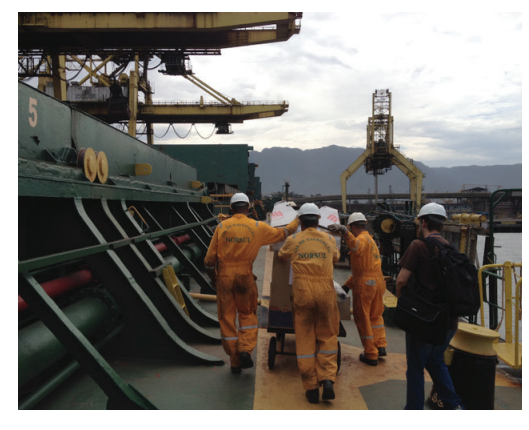

Figura 63 Acesso ao navio. Tanque de lastro escolhido para a instalação do sistema. B) transporte dos equipamentos

Toda a atividade de instalação dos equipamentos a bordo do navio contou com o forte apoio da tripulação, que foi essencial para que o objetivo fosse concluído. Deste modo, é importante frisar que para atividades desta natureza, o comprometimento da tripulação e empresa são essenciais. A tarefa de instalação foi dividida em duas etapas: (1) instalação dos sensores no tanque de lastro; (2) instalação dos equipamentos de comunicação e painel solar no mastro do navio, bem como, passagem dos cabos para instalação da central de controle dentro do paiol do mestre.

A etapa (1) contou com esforço da tripulação para abertura do casco do navio para a passagem dos cabos. Cada sensor instalado dentro da gaiola tinha um cabo que deveria ser ligado ao final da instalação junto a central de controle. Para isso, foi desenvolvido um sistema de flange com prensa cabos para garantir a estanqueidade do navio e a passagem dos cabos do tanque até a central de controle (Figura 64).

Ao mesmo tempo que foram realizados os furos e soldagens das flanges, outra equipe estava dentro do tanque de lastro instalando a gaiola com os sensores. Cabe frisar, que a instalação da gaiola dentro do tanque foi uma tarefa árdua e desgastante devido o espaço ser confinado. 
C)

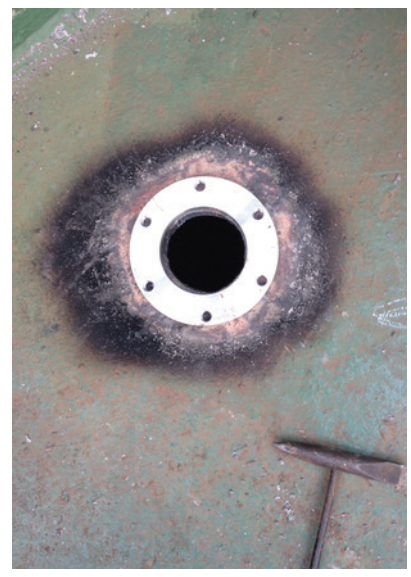

D)

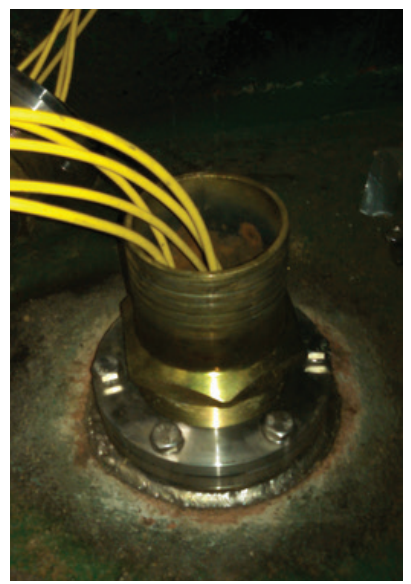

E)

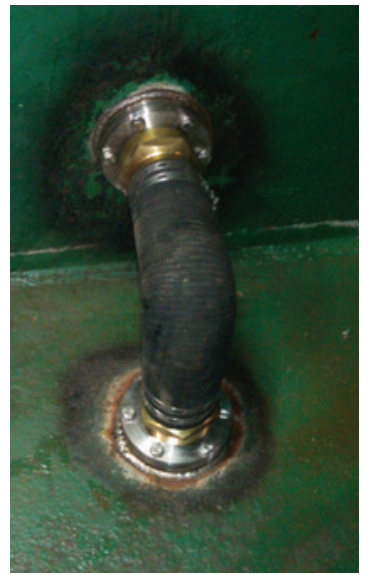

Figura 64 Adaptação necessária no convés superior do navio para a passagem dos cabos dos sensores. C) mostra a abertura realizada com um sistema de flange para permitir a fixação da flange com prensa cabos (D) e acoplamento com a parede do paiol do mestre com uma mangueira para proteção dos cabos dos sensores (E)

F)
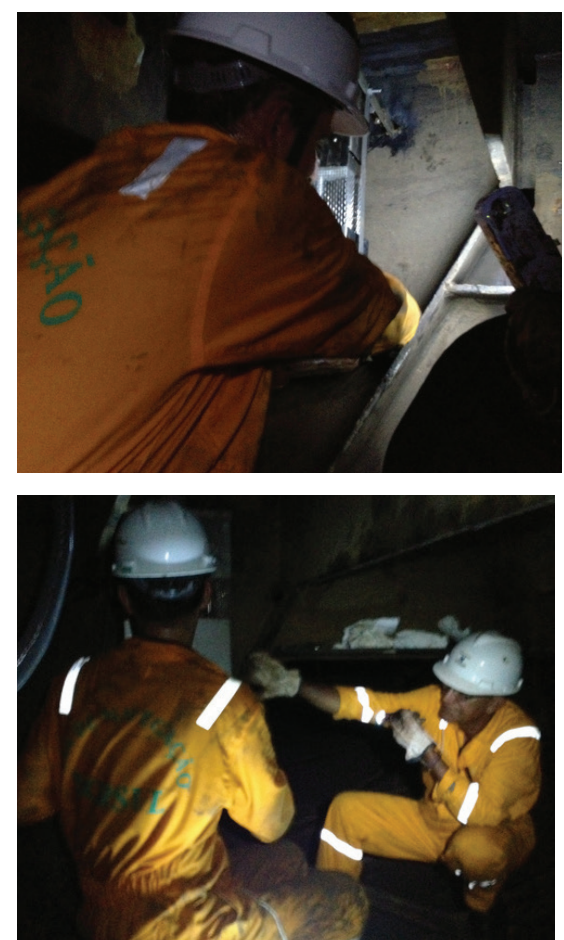

G)

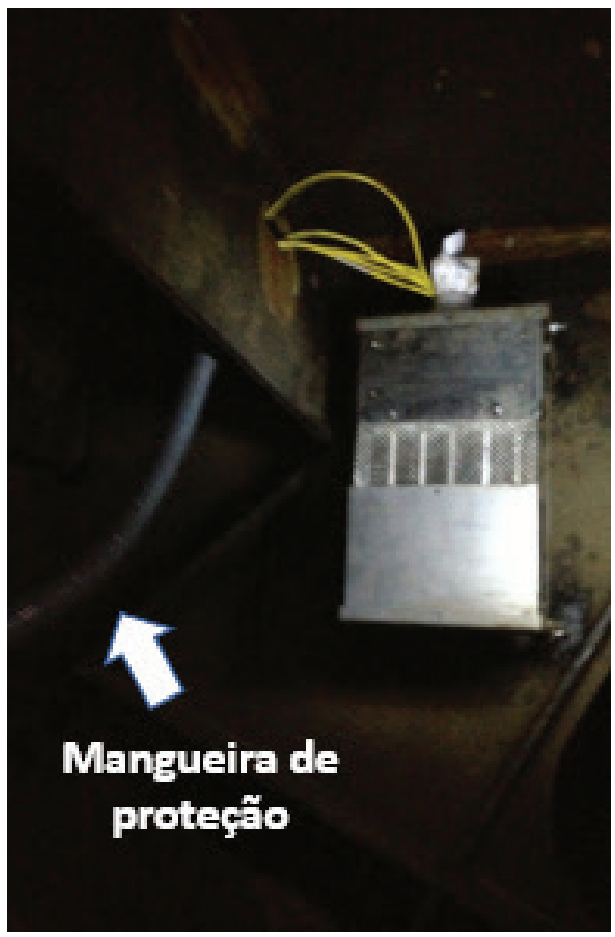

Figura 65 Processo de instalação da gaiola dentro do tanque de lastro do navio (F). Os cabos dos sensores foram envolvidos por uma mangueira protetora para evitar a deterioração dos mesmos (G) 
Uma vez que foi instalado a gaiola dentro do tanque e os cabos foram passados, fechou-se o sistema de flange acoplando-as com a mangueira e passando os cabos para dentro do paiol do mestre.

Ao mesmo tempo, todo os sistemas de comunicação e alimentação também foram instalados no mastro do navio. Inicialmente, foram instaladas a antena e o painel solar.

$\mathrm{H})$

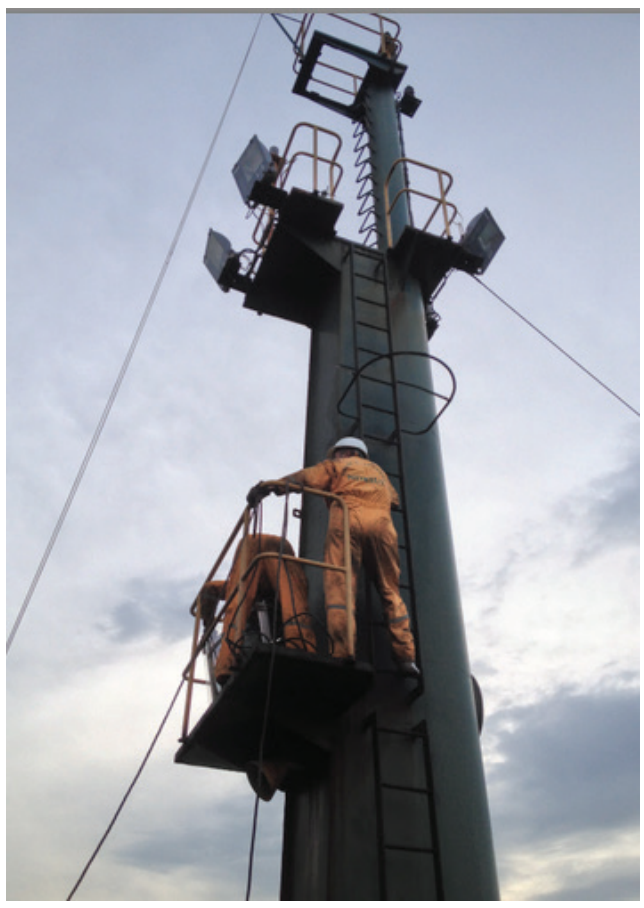

I)

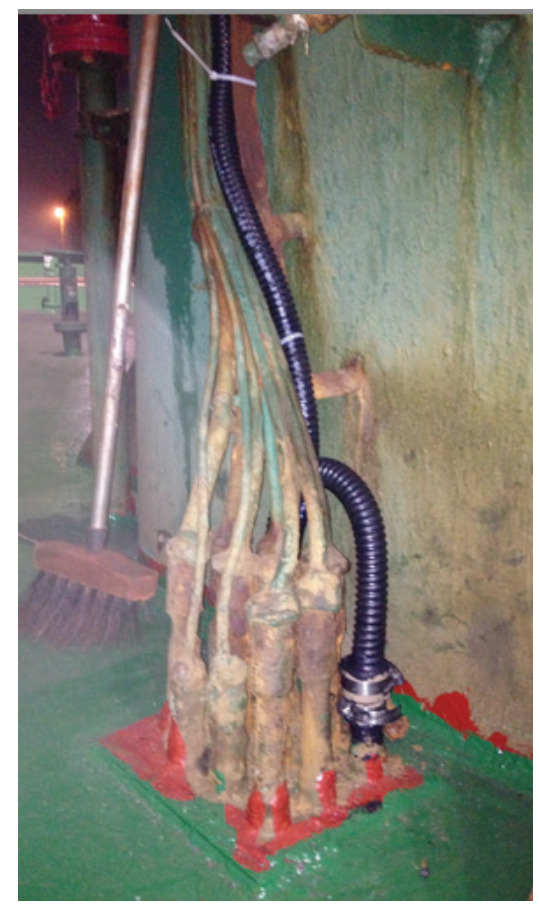

Figura 66 Instalação dos equipamentos no mastro do navio e passagem dos cabos para a parte interna do paiol do mestre

A instalação destes equipamentos em conjunto findou-se por volta das $22 \mathrm{~h} 00$. Ao longo deste processo dificuldades naturais foram encontradas para encontrar a passagem dos cabos, ligações, entre outras, que são naturais desta atividade.

A próxima etapa foi a instalação do sistema de controle dentro do paiol do mestre. Todos os cabos que vinham dos tanques de água de lastro, bem como, os que desciam do mastro deveria chegar ao mesmo destino, o painel de controle. Para isso, a equipe teve a necessidade de procurar os conduites que levavam os cabos e até o local onde o painel de controle foi instalado. Uma vez vencida esta etapa o sistema todo foi ligado. 

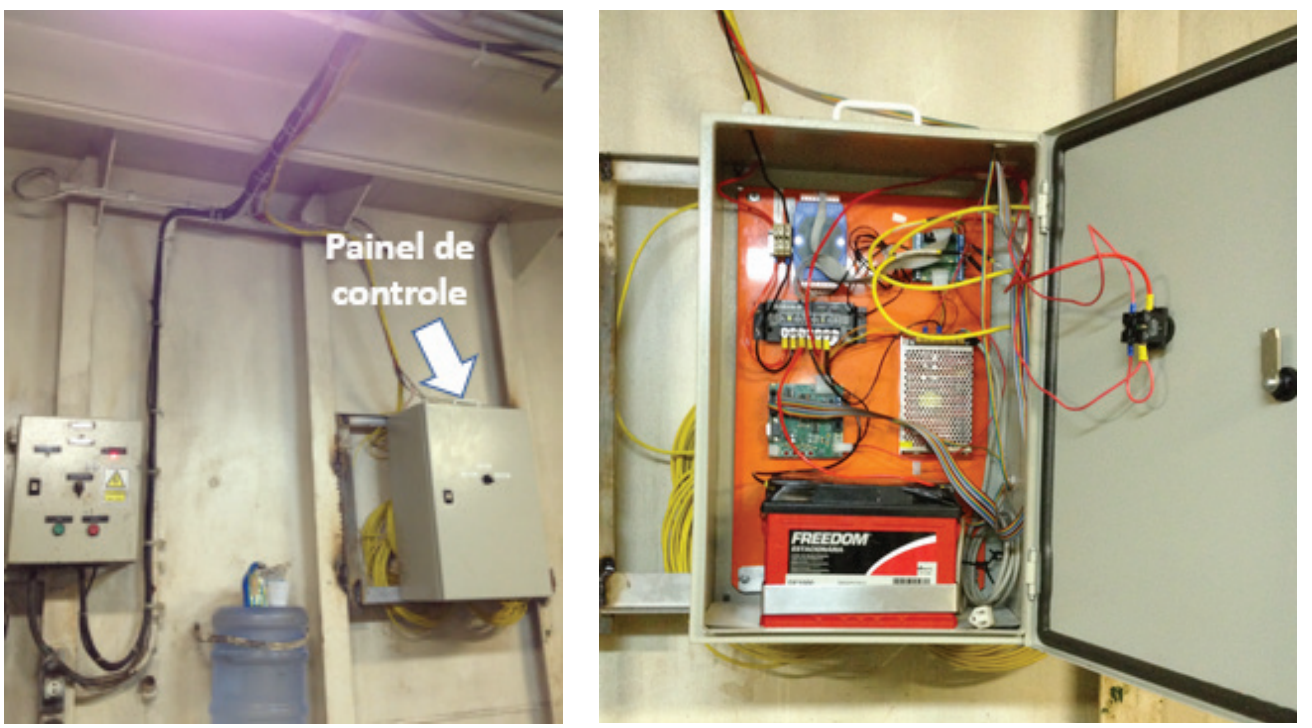

Figura 67 Instalação do sistema de controle dentro do paiol do mestre

Já era por volta das 03:00 do dia 10 de abril quando a equipe retornou para a cidade de São Paulo e o sistema ficou instalado a bordo do navio.

Durante a viagem de retorno foi possível verificar a primeira leitura dos sensores, pois devido a passagem do satélite a transmissão dos dados ocorria somente a cada uma hora. Deste modo, a equipe teve a certeza que o sistema estava funcionando.

Nos dias seguintes ficamos acompanhando os dados dos sensores em função da posição do navio. Quando o navio partiu e realizou sua viagem com destino ao um porto na Argentina foi possível acompanhar o passo a passo da viagem, correlacionando a posição geográfica do navio com os parâmetros da leitura do tanque de lastro.

Assim, durante a viagem do navio é possível verificar os parâmetros físicos químicos da água, por meio do website desenvolvido para o monitoramento das informações coletadas pelos sensores Figura 68.

Nós sabíamos que haviam algumas limitações naturais do sistema que ainda deveriam ser contornadas. A primeira era relativa ao sensor de condutividade utilizado para medir a salinidade da água. $\mathrm{O}$ range do sensor variava de $0 \mathrm{a}$ 42000 uS, que era apto para medir até água salobra com 32 ppt. Como quando saímos do porto o navio lastrou o tanque sabíamos que água que estava dentro do tanque apresentava salinidade acima de 31 ppt, conforme mostrado pelo sensor. Para o experimento ele funcionaria como um indicativo de presença de 
água oceânica que apresentava salinidade na faixa de 35 a 37 ppt, neste caso, mantendo-se sempre como uma linha reta. Os outros parâmetros relativos a temperatura, $\mathrm{pH}$, oxigênio dissolvido e turbidez apresentarem-se coerentes num primeiro momento.

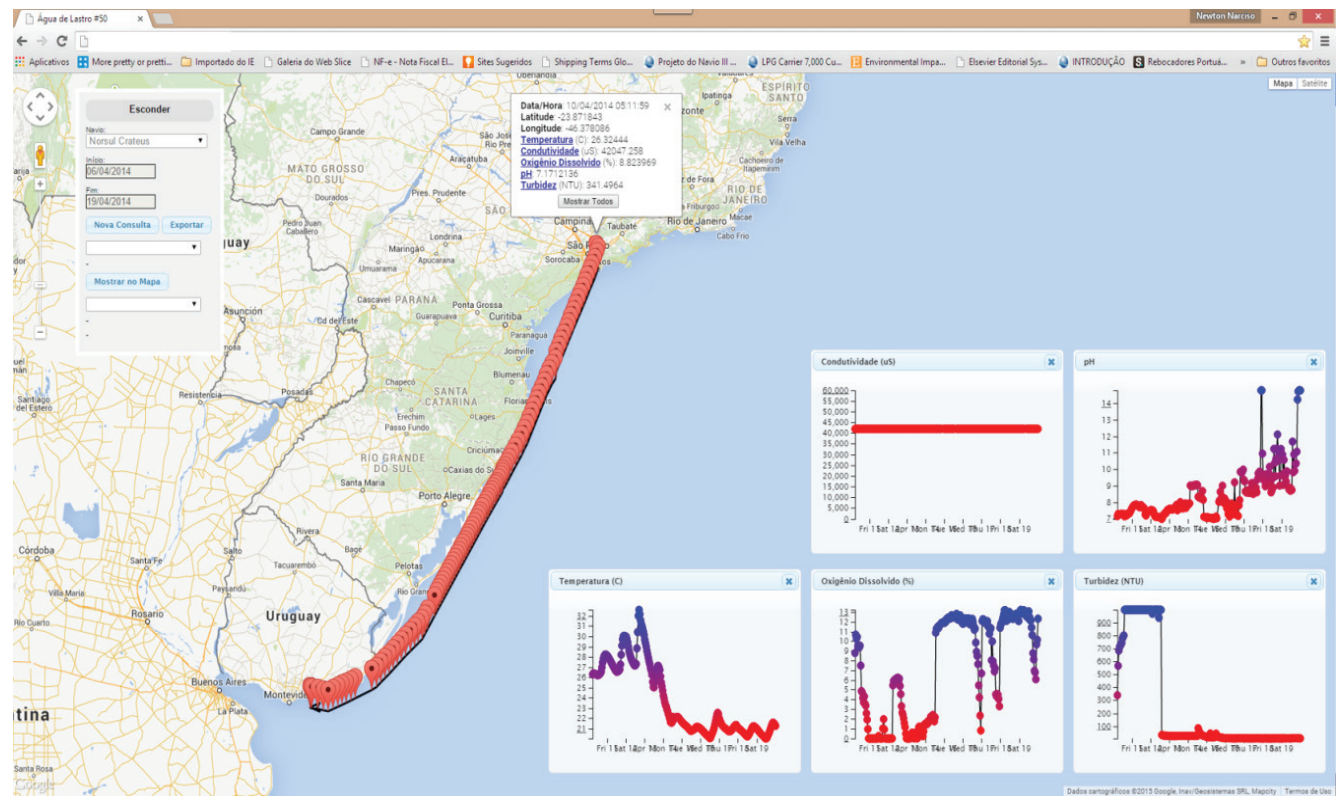

Figura 68 Exemplo de captura de dados pelo sistema sendo apresentados diretamente no website para visualização dos parâmetros físicos químicos da água. As leituras apresentadas foram de dados coletados na primeira viagem do navio em que 0 sistema ainda estava em fase de aprimoramento

Mantivemos contatos com a tripulação do navio que nos informou o momento da troca da água de lastro e pudemos verificar isso principalmente pela mudança da turbidez da água. Após 8 dias de viagem verificamos que o sensor de $\mathrm{pH}$ começou a apresentar problemas de leitura e se deteriorou. Ao longo das viagens do navio continuamos o monitoramento dos parâmetros físicos químicos medidos. Verificamos que durante alguns períodos de tempo o sistema parava de transmitir dados.

Tínhamos ai uma dúvida em relação ao funcionamento do sistema. Durante uma atracação do navio no porto de Santos a equipe visitou o navio para verificar o que estava acontecendo com o sistema de transmissão de dados. Notamos que o sistema de alimentação estava sendo afetado devido ao problema da poeira que se formou sobre o painel solar que afetava a alimentação da bateria e causava falha na alimentação do sistema. 


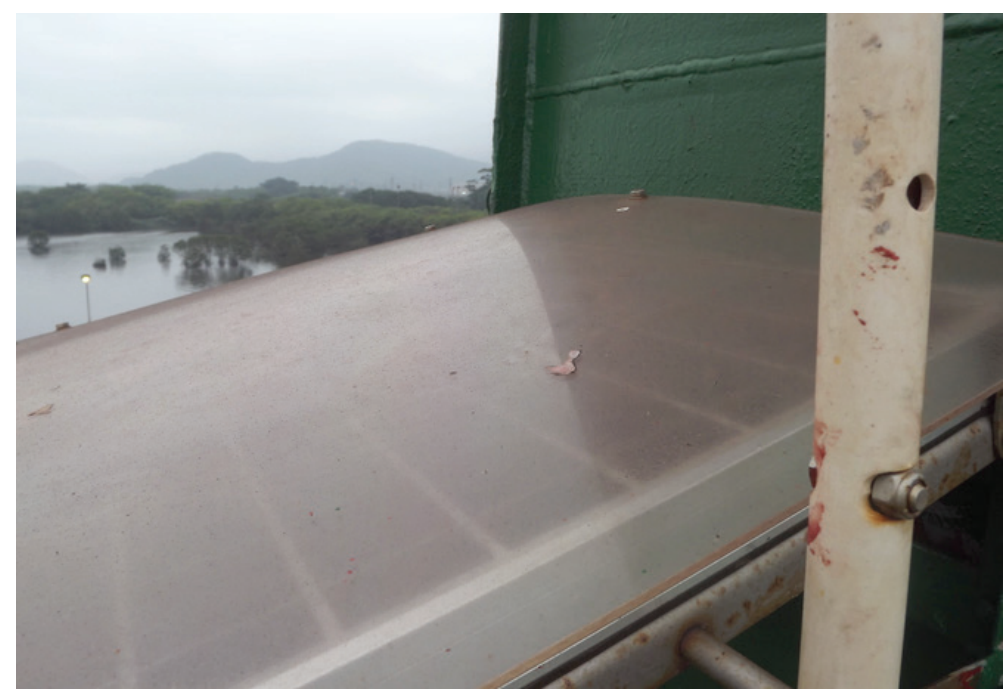

Figura 69 Painel solar afetada pela presença de poeira

Para mitigar o problema da alimentação foi feita uma ligação direta do sistema de alimentação com a fonte primaria de energia elétrica do navio. Ainda durante está inspeção, nós retiramos o sensor de pH e fizemos uma limpeza nos outros sensores que estavam dentro da gaiola. Após a inspeção poucos dias posterior o sensor de temperatura também apresentou problemas de funcionamento.

Continuamos a monitorar o navio por mais de 13 viagens entre abril de 2014 a dezembro de 2015. Somente após a viagem numero 5 é que verificamos que o navio passou a trocar sua água de lastro dentro da região água doce na bacia do rio do Prata na Argentina e o sensor de salinidade passou a registrar a variação dos parâmetros. Durante este período o navio realizou diversas viagens entre Santos e Argentina e depois para os portos da região Nordeste, entre Terminal Marítimo de Ponta da Madeira e porto de Trombetas, realizando operação de lastro na foz do rio Amazonas. Todas as trocas foram percebidas pelo sistema instalado a bordo do navio e os dados medidos foram confrontados com os formulários de água de lastro enviados pela tripulação do navio. Durante as viagens foi possível notar o compromisso da tripulação e da empresa no cumprimento das normas nacionais para o lastro e deslastro do navio. Os resultados deste experimento foram publicados na revista internacional Ocean \& Coastal Management em 2016.

Após estes experimentos realizados o navio enviado para desmantelamento e fez sua contribuição para o conhecimento da dinâmica dentro dos tanques de lastro de navios.

A principal vantagem do sistema desenvolvido foi a possibilidade do monitoramento da qualidade da água ao da viagem do navio. 


\subsection{DISCUSSÃO}

O desenvolvimento de um sistema de monitoramento remoto da qualidade da água de lastro dos tanques buscou conferir maior confiabilidade nas informações fornecidas pelos navios. Considerando que as informações contidas nos formulários de água de lastro são geralmente fornecidas pela tripulação dos navios é necessário sempre que seja efetuada uma verificação da água contida no tanque para confirmar as informações. Ao longo deste livro foi possível verificar alguns exemplos de problemas neste processo.

Por outro lado, esse procedimento aumenta os custos da gestão da água de lastro para o Estado porto. Considerando que a BWMC já entrou em vigor e muitos navios ainda não estão dotados de BWMS, faz necessário ainda a verificação da qualidade da água de lastro dos navios.

É neste sentido, que o sistema desenvolvido mostrou-se como uma opção viável para auxiliar no monitoramento da qualidade da água de lastro despejada nos portos. Como as informações foram coletadas continuamente diretamente dos tanques de água de lastro correlacionado com sua posição geográfica, foi fácil identificar onde iniciou e terminou a troca da água de lastro.

Além disso, o monitoramento da qualidade da água de lastro poderia fornecer ao porto os parâmetros físico químicos da água coletada e despejada. Por exemplo, seria possível determinar qual a turbidez da água despejada em determinada região. Além disso, identificar se água despejada era oriunda de água salgada ou doce. Isso poderia auxiliar também o Estado porto a identificar se o tratamento da água de lastro a bordo do navio durante a viagem pode ter sido afetado em função da turbidez. Para sistemas que utilizam radiação ultravioleta a turbidez da água pode afetar severamente a eficiência do tratamento. Se água coletada é muita turva pode ser um indicador para verificação da qualidade final do tratamento.

Por outro lado, uma vez que o controle da troca da água de lastro em mar aberto deixa de ser manual e passa a ser eletrônico, é possível determinar se eventualmente ocorreu alguma violação do sistema. Como o ciclo de transmissão das informações pode ser contínuo ao longo da viagem do navio, esses parâmetros poderiam ser acoplados aos formulários de água de lastro, limitando assim a possibilidade de fraude das informações.

Contudo, não é incomum o registro de violações do cumprimento da troca da água de lastro. Cerca de 53.503 relatórios de água de lastro foram entregues à Guarda Costeira Americana no período de 2004 e 2005, os quais foram analisados para identificar os pontos de coleta e despejo de água de lastro no país (MILLER et al. 2007). A conclusão foi que cerca de 18.250 embarcações trocaram água de lastro dentro das 200 milhas náuticas próximas à costa dos Estados Unidos. 
Leal Neto (2007) apresentou os principais problemas encontrados num levantamento realizado nos formulários entregue à Marinha do Brasil no período de 2001 a 2002 (maio) resultando em: "grande parte dos formulários foi preenchida incompleta e ou incorretamente; diferentes tipos de formulários, diferentes unidades utilizadas (algumas vezes falta de informação da unidade); falta de dados (data de chegada, nome e posto do oficial responsável); diferentes combinações de tanques na "coleta" e na "descarga" da água de lastro, cópias ilegíveis, escrita incompreensível, dados incoerentes entre as diferentes seções do formulário (número de tanques e/ ou tanques e/ou volumes) e confusão no campo "sea height (m)" entre a profundidade onde ocorreu a troca da água de lastro e altura da onda".

Caron (2007) mostrou inconsistências durante a análise de 808 formulários de água de lastro entregues às autoridades marítimas do Porto de Itajaí no Sul do Brasil. Dos formulários analisados apenas 39 continham dados sobre deslastro, em que 11 não declaram ter feito a troca oceânica; 9 não possuíam a origem de lastro (coordenadas) e 1 não possuía nenhuma coordenada de origem e troca. Do total de formulários $270(33,42 \%)$ apresentavam declaração de que haviam realizado a troca oceânica. Utilizou-se como procedimento de validação do local da troca uma análise das coordenadas geográficas contidas no relatório e conclui-se que do total de 270 declarações de troca $45 \%$ das coordenadas indicavam locais junto à costa, próximo de ilhas, dentro de baias e enseadas, sendo que um dos casos o navio estava aproximadamente $450 \mathrm{~km}$ terra adentro.

Outro estudo realizado pela Agência Nacional de Vigilância Sanitária - Anvisa (2003) apresenta os resultados de 99 amostragens de água de lastro de navios em 9 portos brasileiros. Foi verificado que $62 \%$ das embarcações cujos comandantes declararam ter efetuado a substituição da água de lastro em área oceânica. Contudo, a avaliação mostrou que muitos a fizeram de forma parcial, por possuírem água de lastro com salinidade inferior a 35ppm”.

Desde 2009, os Estados da Califórnia, Nova Iorque e Michigan estudam aumentar em 100 vezes a restrição à eficiência do tratamento em relação a IMO - D2. A previsão era que esta medida entrasse em vigor em 2013, passando para 2017 e finalmente para 2031, devido à falta de indicativo que os sistemas de tratamento atuais sejam capazes de atender estes critérios de zero detecção.

Mesmo com a BWMC em vigor, a busca por soluções de identificação de espécies em tanque de lastro deverá passar por alguma solução remota. Mais uma vez justifica-se a utilização de sistema de monitoramento da qualidade da água de lastro e a localização da troca/tratamento para aumentar a confiabilidade das operações de lastro dos navios. Esse procedimento de instrumentação dos tanques podem permitir que outros tipos de sensores sejam acoplados ao sistema e mais medidas sejam realizadas sobre a água de lastro a bordo dos tanques dos navios. 


\subsection{CONCLUSÃO}

Nós pudemos verificar ao longo deste experimento que o protótipo instalado a bordo de um navio foi eficiente em termos de monitoramento da qualidade da água de lastro.

Os problemas decorrentes do monitoramento serviram de base para melhorar o conhecimento sobre a questão. Além disso, o fato de um sistema remoto ter sido instalado a bordo de um navio conferiu uma contribuição ao conhecimento da dinâmica dentro de um tanque de água de lastro em escala real.

Embora, o sistema tenha sido descontinuado em conjunto com o navio, a equipe de desenvolvimento patenteou o sistema intitulado "MONITORAMENTO DA TROCA E DA QUALIDADE DA ÁGUA DE LASTRO E MÉTODO PARA OBTENÇÃO DE DADOS RELACIONADOS À ÁGUA DO LASTRO”.

Sua aplicabilidade estende ao setor fluvial, além de ser o primeiro sistema desenvolvido no Brasil com essa característica de monitoramento da água de lastro de navios.

\subsubsection{Agradecimentos}

Agradecemos a equipe coordenada pelo prof. Dr. Marcelo N. P. Carreño, bem como, aos pesquisadores Prof. Dr. Marco Isaías Alayo Chávez, Fábio Colombo, Alexandre Lopes do Laboratório de Microeletrônica da Escola Politécnica da Universidade de São Paulo, pela participação no projeto e no desenvolvimento das soluções necessárias para seu funcionamento.

Agradecemos ao Eng. Naval Geert Jan Prange que desenvolveu o primeiro conceito deste sistema. A companhia de navegação Norsul que permitiu que nós instalássemos este sistema a bordo do navio M/V Norsul Crateus, bem como, a sua tripulação que sempre forneceu o apoio necessário durante nossas visitas ao navio.

Ao CNPq que forneceu o subsidio necessário para o desenvolvimento desta pesquisa e a FINEP por meio do projeto ALOHA.

\subsection{REFERÊNCIAS}

AGÊNCIA NACIONAL DE VIGILÂNCIA SANITÁRIA. Água de lastro. Projetos GGPAF. 2002-2003. Brasil.

CARON JUNIOR, A. Avaliação do risco de introdução de espécies exóticas no porto de Itajaí e entorno por meio de água de lastro. 2007. Dissertação (mestrado) apresentada à Universidade do Vale do Itajaí em Ciências e Tecnologia Ambiental. 2007. 
DOBROSKI, N., C. SCIANNI, and L. TAKATA. "2011 update: ballast water treatment systems for use in California waters." (2011).

LEAL NETO, A.C. Identificando similaridades: Uma aplicação para a avaliação de risco de água de lastro. Tese (Doutorado) apresentada à Universidade Federal do Rio de Janeiro em Ciências em Planejamento Energético. 2007.

MILLER, A. W., et al. "Status and trends of ballast water management in the United States." Third Biennial Report of the National Ballast Information Clearinghouse.(January 2004 to December 2005). Smithsonian Environmental Research Center. Report Submitted to the United States Coast Guard (2007).

PEREIRA N.N, BRINATI HL. Onshore ballast water treatment: A viable option for major ports. Marine Pollution Bulletin. 2012.

PEREIRA N.N, PRANGE, G.J., Ship Ballast Tank Sediment Reduction Methods. Naval Engineers Journal. 2013.

BATISTA, William R., et al. "Which Ballast Water Management System Will You Put Aboard? Remnant Anxieties: A Mini-Review.” Environments 4.3 (2017): 54.

BAKALAR, Goran. "Review of interdisciplinary devices for detecting the quality of ship ballast water." SpringerPlus 3.1 (2014): 468.

CURTO, A. Lo, et al. "Ballast water compliance monitoring: A new application for ATP.” Journal of Sea Research (2017).

RAID et al. (2007) - Identifying, Verifying, and Establishing Options for Best Management Practices for NOBOB Vessels. 
